\title{
Influence of Surface Treatment of Polyimide Film on Adhesion Enhancement between Polyimide and Metal Films
}

\author{
Soo-Jin Park, ${ }^{\dagger *}$ Eun-Jung Lee, and Soo-Han Kwon \\ ${ }^{\dagger}$ Department of Chemistry, Inha Lniwersity, Incheon 402-751, Korea. ${ }^{\circ}$ E-mail: siparkatma.ackr \\ Department of Chemistry, Chungbuk National Lniversity, Cheongit 361-763, Korea \\ Recerved October 27, 2006
}

\begin{abstract}
In this work. the effects of chemical treatment of polyimide films were studied by FT-IR. X-ray photoelectron spectroscopy (XPS), atomic force microscopy (AFM) and contact angles. The adhesion characteristics of the films were also investigated in the peel strengths of polyimide/aluminum films. The increases of surface functional groups of $\mathrm{KOH}$-treated polyimide films were greatly correlated with the polar component of surface free energy. The peel strength of polyimides to metal substrate was also greatly enlanced by increasing the $\mathrm{KOH}$ treatment time. which can be attributed to the formation of polar functional groups on the polyimide surfaces. resulting in enhancement of the work of adhesion between polymer film and metal plate.
\end{abstract}

Key Words : Polyimide. Chemical treatment. Adhesion characteristics. T-peel test

\section{Introduction}

Metal-coated polymers are used in various technologies for a wide range of applications. Thin film metallized polymers are used extensively in radio and electronics. cryogenics engineering. computer teclunology. solar-energy converters. etc. 1.2 With the increase of the use of metallized polymers in the microelectronic industry, an understanding of the mechanism responsible for adhesion between metals and polymers has become of increasing importance. Among the polymers suitable for microelectronic applications. polyimide has received a great attention due to their thermal and chemical stability; low dielectric constant high electrical resistivity. and relative ease of processing into coating and films. ${ }^{3-6}$ For all these reasons. polyimides have been widely used in microelectronics as dielectric spacing layers. protective coatings and substrates for metal thin films. replacing traditional inorganic insulators such as $\mathrm{SiO}_{2}$ in many applications. $^{7-10}$ In these and other applications good adhesion between polyimide and a metal substrate is required.
However, the adhesion of metals directly to the polyimides is usually poor due to the inertness of polyinide surfaces. Failure to activate a polyimide surface will normally cause the subsequent coatings to be poorly adhered and easily cracked. blistered or otherwise removed. ${ }^{11.12}$ Various surface treatments and modification methods have been used to enhance the metal to polyimide adhesion. These include the uses of ion beam. photografting. plasma and sputtering. Most of these methods require high vacuum equipment and the productivity is low: thus they are not economically feasible. These methods may also introduce foreign materials and undesirable modified layers into the interfaces. resulting in possible reliability failure. 13-15 $^{-15}$

Interests in wet-process surface modifications of polyimides have increased due to simplicity and low cost. Polyimide films are resistant to most solvents and chemicals. but they react with oxidizing or reducing agents. However, if the concentrations of the chemical reagents. reaction temperatures. and reaction time are well controlled the reactions can be confined to the surface. ${ }^{16}$

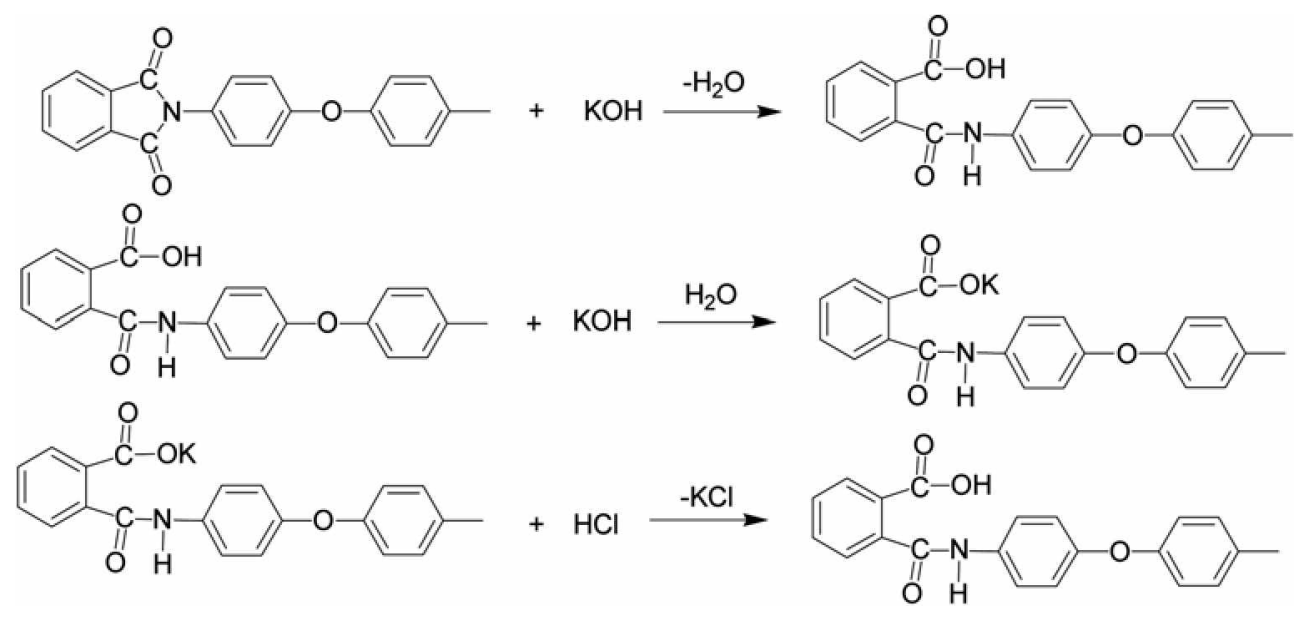

Figure 1. Imide ring opening in polyimide film by $\mathrm{KOH}$ treatment at room temperature. 
In this work. polyimide films were initially modified with $\mathrm{KOH}$ solution as a function of $\mathrm{KOH}$ treatment time and then reacted with $\mathrm{HCl}$ solutions to polyamic acid surfaces (Figure 1). We attempt to investigate the effect of mechanical properties of the PI films and the influences of surface properties on the adhesion strength and mechanical properties of polyimide films are also studied by a peel test with a metal laỵer.

\section{Experiments}

Materials and sample preparation. Pyromellitic dianhy dride-oxdianiline (PMDA-ODA) polyimide type 2545 (DuPont) is spun onto aluminum plate (Fukuda. $>99.5 \% .50 \mu \mathrm{m}$ ) and is then cured by following a standard recipe. Poly imide films were treated with $10 \mathrm{wt} \% \mathrm{KOH}$ aqueous solution at room temperature in the range of 0 to $80 \mathrm{~min}$ in order to give the corresponding potassium polyamate. The excess of $\mathrm{KOH}$ was removed by washing with water $(2 \times 3 \mathrm{~min})$. Then the polyimides were treated with $10 \mathrm{wt} \% \mathrm{HCl}$ aqueous solution at room temperature for $5 \mathrm{~min}$. The modified surfaces would be polyamic acids. and the polymides were dried under vacuum for another $12 \mathrm{~h}$

Surface properties. FT-IR spectra of chemical treated polyimide were obtained using a MIDAC M2000. The scans were shown from 400 to $4000 \mathrm{~cm}^{-1}$ and required $40 \mathrm{~s}$ to complete

The X-ray photoelectron spectroscopy (XPS) measurement of polyimide surfaces was performed using a VG Scientific ESCA LAB MK-II spectrometer equipped with a Mg-K $\alpha \mathrm{X}$ ray source. The base pressure in the sample chamber was controlled in the range fixed the $\mathrm{C}_{\mathrm{ls}}$ peak at $284.6 \mathrm{eV}$ considering the neutralization

Surface morpology. The surface free energy of the $\mathrm{KOH}-$ treated poly imide film was determined at $20 \pm 1{ }^{\circ} \mathrm{C}$ using a sessile drop method on a Surface \& Electro-Optic Co. SEO $300 \mathrm{~A}$. Four different wetting liquids. distilled water diiodomethane. ethlyene glycol. and ethylene glycerol were selected. For each sample. every calculated contact angle was an average of 10 measurements with a standard deviation below $1^{\circ}$. For this work, the surface tension and its components for the wetting liquids are shown in Table 1

The surface morphologies of the chemical treated polyimide were studied by atomic force microscopy (AFM). suing a Digital Instruments Inc. Nanoscope III microscope. In each case. an area of $10 \times 10 \mu \mathrm{m}$ was scanned using the tapping mode. The AFM observation was carried out at ambient pressure and room temperature. The surface roughness

Table 1. Surtace free energy characteristics of the testing liquids, measured at $20^{\circ} \mathrm{C}$

\begin{tabular}{cccc}
\hline & $\gamma_{L}^{\frac{1}{4}}\left(\mathrm{~m}_{\mathrm{T}}^{\mathrm{\top}} \cdot \mathrm{m}^{-\hat{4}}\right)$ & $\gamma_{L}^{S P}\left(\mathrm{~mJ} \cdot \mathrm{m}^{-\hat{\imath}}\right)$ & $\gamma_{L}\left(\mathrm{~m} \cdot \mathrm{\top} \cdot \mathrm{m}^{-2}\right)$ \\
\hline Water & 21.8 & 51.0 & 72.8 \\
Diiodomethane & 50.42 & 038 & 508 \\
Ethylene glycol & 31.0 & 16.7 & 477 \\
Glycerol & 33.9 & 298 & 637 \\
\hline
\end{tabular}

of the polyimides was evaluated in terms of the arithmeticmean of the roughness $(R a)$ and the rootmean-square (RMS) of the roughness.

Adhesion characteristics. The adhesion strength of the $\mathrm{KOH}$-treated polyimides/aluminum was detemined by measuring the T-peel adhesion strength. The aluminum foil used as a metal layer for the T-peel test was supplied by Fukuda with a thickness of $50 \mu \mathrm{m}$, and the epoxy resin was the diglycidyl ether of bisphenol A (YD-128. supplied from Kukdo Chem. Co.). The curing agent was diaminodiphenyl methane (DDM. 1:1 of equivalence ratio) purchased from Aldrich Chem. Each sample was cured for $2 \mathrm{~h}$ at $120^{\circ} \mathrm{C}$. The T-peel test (ASTM 1876-72) was measured at a peel rate of $254 \mathrm{~mm} / \mathrm{min}$ using Lloyd LR5K.

\section{Results and Discussion}

Surface properties. The polyimide surface was reacted with aqueous $\mathrm{KOH}$ solution to yield potassium polyamate, which was subsequently acidified by $10 \mathrm{wt} \% \mathrm{HCl}$ to polyamic acid. Figure 2 shows the FT-IR spectra of pure polyimide. $\mathrm{KOH}$-treated polyimide and $\mathrm{HCl}$-treated polyimide. The key features of the FT-IR spectrum of the polyimide film are listed in Table $2 .{ }^{17}$ In Figure 2, the $1513 \mathrm{~cm}^{-i}$ peaks of the poly imide were scaled to a constant since the aromatic skeletons remained unaltered after the chemical treatments. The changes to the other FT-IR peaks of the modified polyimide surfaces were thus clearly revealed.

In Figure 2(a). the characteristic absorption bands of the pure polyimide appear near $1780(\mathrm{C}=\mathrm{O}$ in phase), 1720 ( $\mathrm{C}=\mathrm{O}$ out of phase). $1513\left(\mathrm{C}=\mathrm{C}\right.$ in $\left.\mathrm{C}_{6} \mathrm{H}_{6}\right), 1370(\mathrm{C}=\mathrm{O}$ in imide). $1100\left((\mathrm{OC})_{2} \mathrm{NC}\right.$ in imide), and $720 \mathrm{~cm}^{-1}$ (imide ring deformation). After treatment in $\mathrm{KOH}$ solution. in Figure 2(b). the intensities of the imide structures at 1780 and 1720 $\mathrm{cm}^{-1}$ peak were reduced. The shifting of the peak $1370 \mathrm{~cm}^{-1}$ indicate that the imide structures of the pure poly imide were hydrolyzed into the amide structures in potassium polyamates and polyamic acids after washing and acidification. The characteristic absorption bands of the polyamic acid

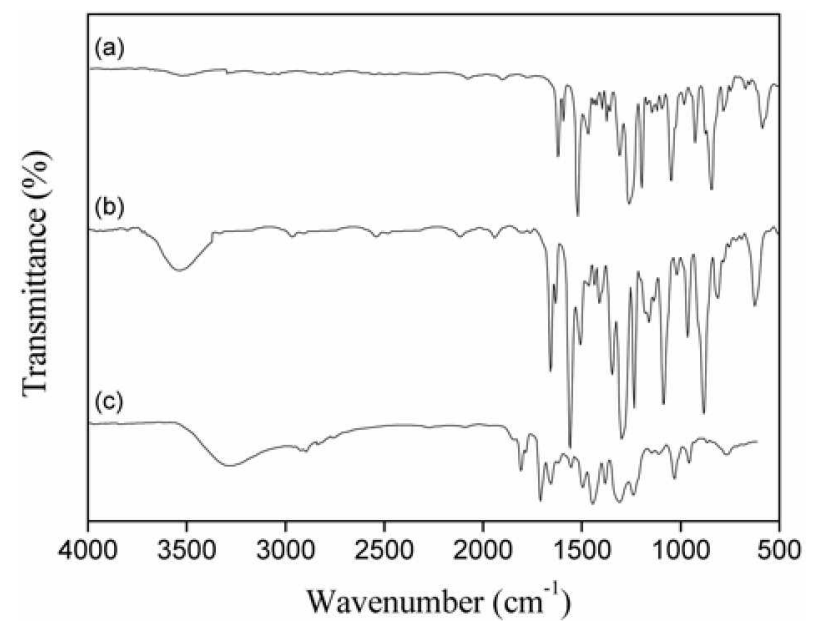

Figure 2. FT-IR spectra of polyimide films; (a) pure poltimide, (b) 10 w. $\% \mathrm{KOH}$ treatment and (c) 10 wt. $\% \mathrm{HCl}$ treatment. 
Table 2. FT-IR peak assignment of the surface treated polymide tilms

\begin{tabular}{cc}
\hline Peak position $\left(\mathrm{cm}^{-1}\right)$ & Peak assigmment \\
\hline $3600-2500$ & $(\mathrm{~N}-\mathrm{H})$ and $(\mathrm{O}-\mathrm{H})$ radiplication \\
$3500-3100$ & $(\mathrm{~N}-\mathrm{H})$ in amide \\
1780 & $(\mathrm{C}=\mathrm{O})$ in phase \\
1720 & $(\mathrm{C}=\mathrm{O})$ out-of-phase \\
1650 & $(\mathrm{C}=\mathrm{O})$ in amide \\
1595 & $\left(\mathrm{COO} \mathrm{O}^{-1}\right)$ \\
1513 & $(\mathrm{C}=\mathrm{C})$ in $\left.\mathrm{C}_{6} \mathrm{H}_{3}\right)$ \\
1370 & $(\mathrm{C}-\mathrm{N})$ in inide \\
1100 & $(\mathrm{OC}) \mathrm{NC}$ in inide \\
720 & imide defornations \\
\hline
\end{tabular}

Table 3. Normalized areas and atomic compositions obtained by XPS high resolution spectra for the Al metal-polvimide interface as a function of treatment time

\begin{tabular}{ccccc}
\hline \multirow{2}{*}{$\begin{array}{c}\text { Treatment time } \\
\text { (mini) })\end{array}$} & \multicolumn{3}{c}{ Total area (\%) } & $\mathrm{O}_{1 \mathrm{~s}} / \mathrm{C}_{\mathrm{ls}}$ \\
\cline { 2 - 5 }$(285 \mathrm{eV})$ & $\mathrm{O}_{1 \mathrm{~s}}(533 \mathrm{eV})$ & $\mathrm{N}_{\mathrm{ls}}(398 \mathrm{eV})$ & \\
\hline 0 & 25.4 & 36.8 & 37.8 & 1.448 \\
20 & 22.3 & 46.5 & 30.6 & 2.085 \\
40 & 21.2 & 51.9 & 25.7 & 2.448 \\
60 & 20.5 & 58.3 & 21.2 & 2.843 \\
80 & 21.2 & 57.6 & 20.7 & 2.716 \\
\hline
\end{tabular}

appear near 3400-2400 (O-H in carboxylic). 3500-3100 (N$\mathrm{H}$ in amide). 1650 ( $\mathrm{C}=\mathrm{O}$ in amide). $1535(\mathrm{C}=\mathrm{O}$ in amide). and $1513 \mathrm{~cm}^{-1}\left(\mathrm{C}=\mathrm{C}\right.$ in $\left.\mathrm{C}_{6} \mathrm{H}_{5}\right)$ and the $1595 \mathrm{~cm}^{-1}$ peak disappears. The hydrolysis reactions can be further confirmed by the appearance of the peaks for carboxylate ions in potassium polyamates and carboxyl acids in polyamic acids. The peak at $1418 \mathrm{~cm}^{-1}$ is due to the vibrations of $-\mathrm{OH}$ in $-\mathrm{COOH}$ and $\mathrm{C}=\mathrm{O}$ in $-\mathrm{COO}$ - In both Figure 2 (b) and (c), the intensities of the imide structures at 1780.1720 . and 1370 $\mathrm{cm}^{-1}$ peaks were reduced but not completely eliminated. suggesting that only the uppermost layers of the polyimide were hýdrolyzed.

Table 3 shows the normalized area and atomic composition obtained by XPS for the polyimides as a function of treatment time. XPS result of polyimide shows carbon. nitrogen, and oxygen (binding energy 285,404 and $532 \mathrm{eV}$. respectively'). And it represents the $\mathrm{O}_{15} / \mathrm{C}_{1 \mathrm{~S}}$ ratios of the poly inides before and after $\mathrm{KOH}$ treatment. As a result the $\mathrm{O}_{18} / \mathrm{C}_{1 \mathrm{~S}}$ ratios of the polyimide increased with the treatment times. which can be attributed to the increase of carbonoxygen functional groups of polyimide surfaces by the treatment. $^{\text {ss }}$

Surface morpology. The concept of surface free energy. $\gamma$, for physical interactions which can be resolved into a London dispersive component $(L)$ and specific (SP) component is ${ }^{19,30}$

$$
\gamma=y^{3}+y^{i}
$$

The change in free energy of the interface is called the work of adhesion $\left(\mathrm{W}_{\mathrm{A}}\right)$ and can be expressed as

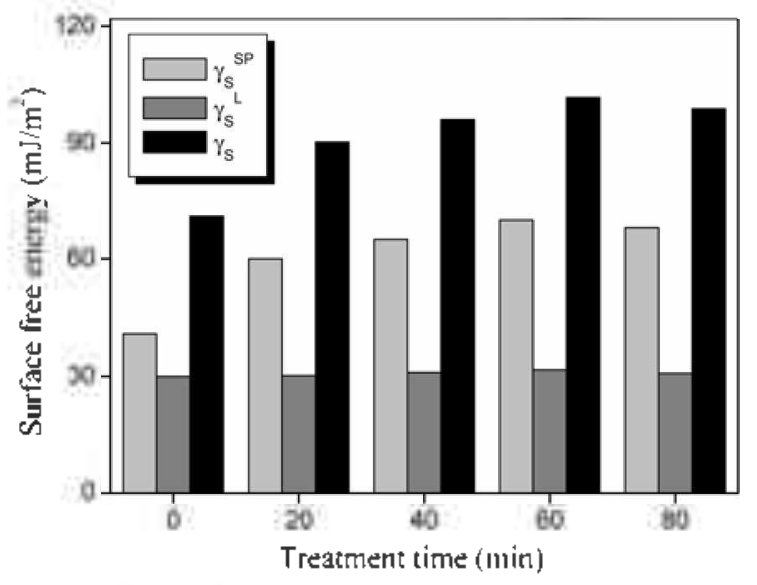

Figure 3. Surtace tree energies and their components of polyimide film as a function of $\mathrm{KOH}$ treatment time.

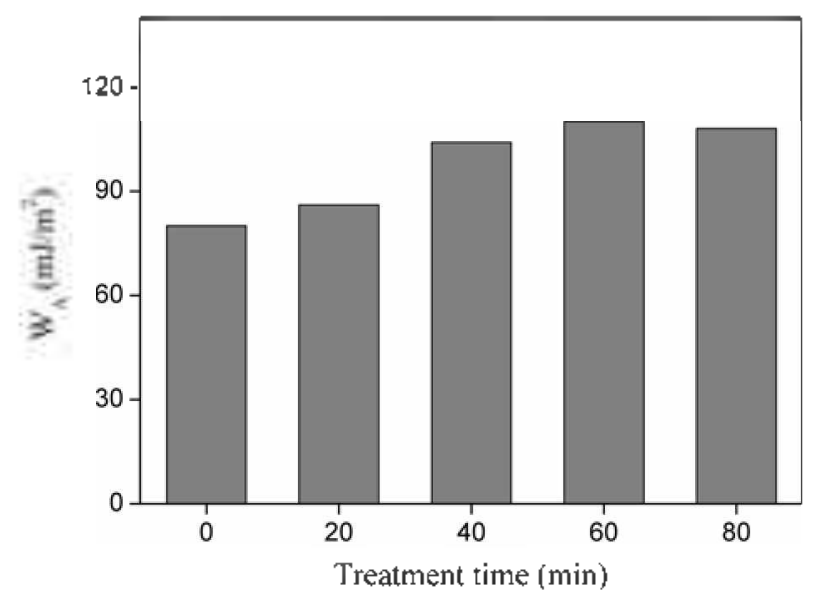

Figure 4. Work of adhesion of the aluminum metal plate-polyimide interface.

$$
\mathrm{W}_{\mathrm{A}}=\gamma_{S^{*}}+\gamma_{\mathrm{SL}}-\gamma_{S^{-}}
$$

Combining equations (1) and (2) yields the following equation:

$$
\mathrm{W}_{\mathrm{A}}=\gamma_{\mathrm{LI}} \cdot(1+\cos \theta)
$$

Work of adhesion represents the energy of attraction between molecules across the interface. The wettability of a solid surface by a liquid is judged by the magnitude of contact angle: the lower the contact angle is, the more wettable the surface is.

Figure 3 shows the results of surface free energies of the $\mathrm{KOH}$-treated polyimides as a function of $\mathrm{KOH}$ treatment times. As a result, it is observed that the polar component of surface free energy is largely increased with increasing $\mathrm{KOH}$ treatment times. These behaviors can be interpreted as the fact that the $\mathrm{KOH}$ treatment of the polyimide surfaces produces various oxygen complexes in hydrophobic face polarity and wettability. resulting in enhancing the total surface free energy. It is also found that dispersive components of the $\mathrm{KOH}$-treated polyimides are not increased. This result indicated that $\mathrm{KOH}$ treatment can not cause the 


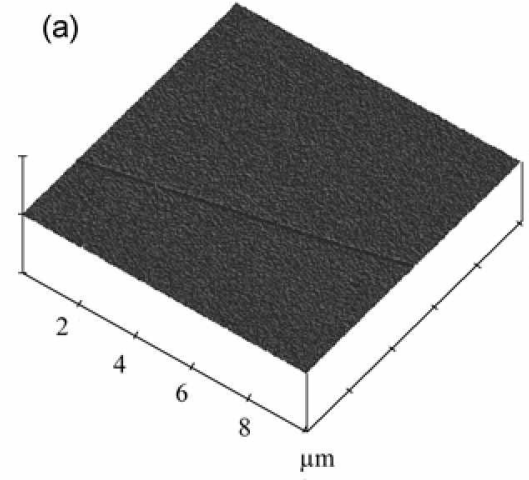

(c)

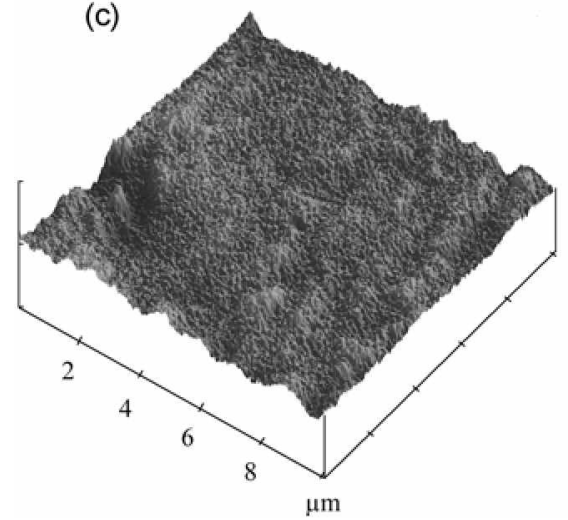

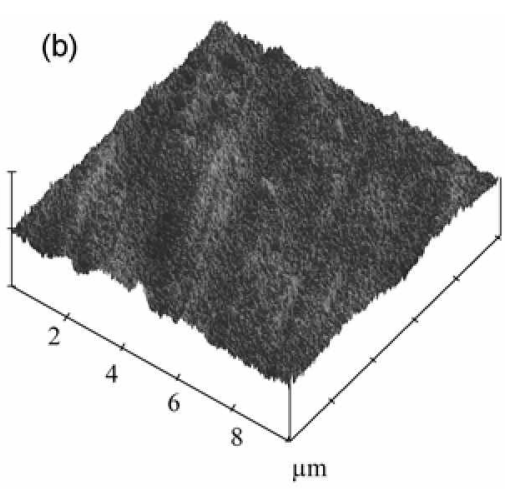

(d)

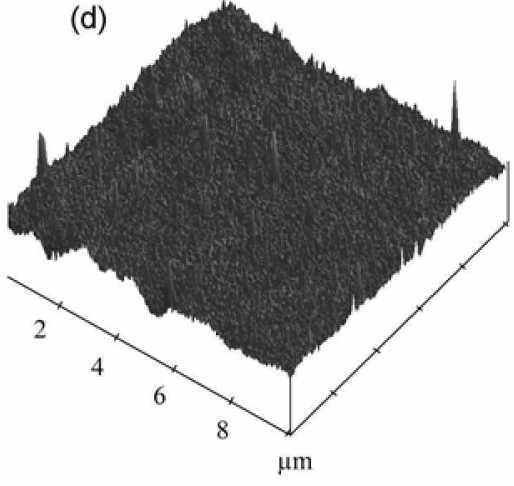

(e)

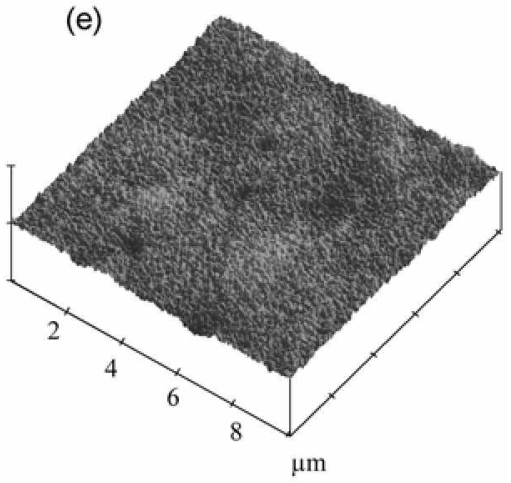

Figure 5. Three-dinensional AFM spectra of polyninide films as a function of treatment time; (a) 0, (b) 20 , (c) 40 , (d) 60 , and (e) 80 min.

increase of the dispersive component. ${ }^{21}$

Figure 4 shows the results of work of adhesion of the $\mathrm{KOH}$-treated polyimides. The work of adhesion of the pure polyimide is about $86 \mathrm{~mJ} / \mathrm{m}^{2}$ and the work of adhesion of the polyimide has increased as the time of treatment to $\mathrm{KOH}$ is increased. The maximum work of adhesion of the polyimide which is treated with $\mathrm{KOH}$ within $60 \mathrm{~min}$ is about $110 \mathrm{~mJ} /$ $\mathrm{m}^{2}$.

The surface morphology is of great importance for the surface wettability of the polymer films. In this work. AFM was employed to examine the morphological changes induced on the $\mathrm{KOH}$-treated polyimide. The differences in morphology after surface treatment further support variation in the relative of amounts of ablation. chain scission. and other functionalization. Figure 5 shows the three-dimensional AFM images of the $\mathrm{KOH}$-treated poly imide as a function of the treatment time. and Figure 6 shows the aritlumetic mean of the roughuess $(\mathrm{Ra})$ and the root-mean-square (RMS) of the roughness. The Ra and RMS roughness of the pure polyimide was about 0.548 and $0.742 \mathrm{~nm}$. respectively: The $R a$ roughness values of the $\mathrm{KOH}$-treated polyimide at the treatment time of $20,40,60$ and $80 \mathrm{~min}$ were increased to $4.825,5.367,5.534$ and $3.145 \mathrm{~nm}$. respectively. Also the RMS roughness values of the $\mathrm{KOH}$-treated polyimide at the treatment time of $20,40.60$. and $80 \mathrm{~min}$ were increased to $6.475,6.787,7.521$. and $4.053 \mathrm{~nm}$. respectively. We concluded that the treatment time controls the oxygen atom and as a result reactive etching of the polyimide surface leads to the surface morphological changes.

Adthesion characteristics. A study on the influence of wet

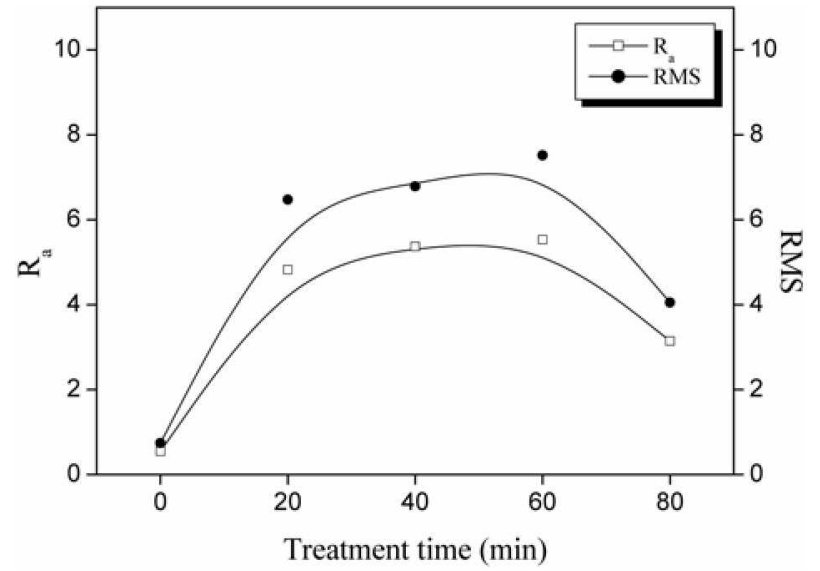

Figure 6. $R a$ and RMS of polymide films as a function of treatment time.

chemical treatments on the evolution of polymer surface roughness is important in order to evaluate the adhesion strength of plated metals atop of polymers. A good adhesion between the metal and the polymer is of prime importance for the reliability of the interconnection. By the chemical treatment of the surface. its characteristics (physical and chemical) can be changed into the increase of adhesion. It is obvious that the surface properties of the polymer are important for the adhesion of the metal to the polymer. Hence there is an intense research recently on improving the adhesion of plated aluminum onto polymer surfaces. Figure 7 represents the peel strength values of polyimide/aluminum samples as a function of $\mathrm{KOH}-$ treatment times. These adhe- 


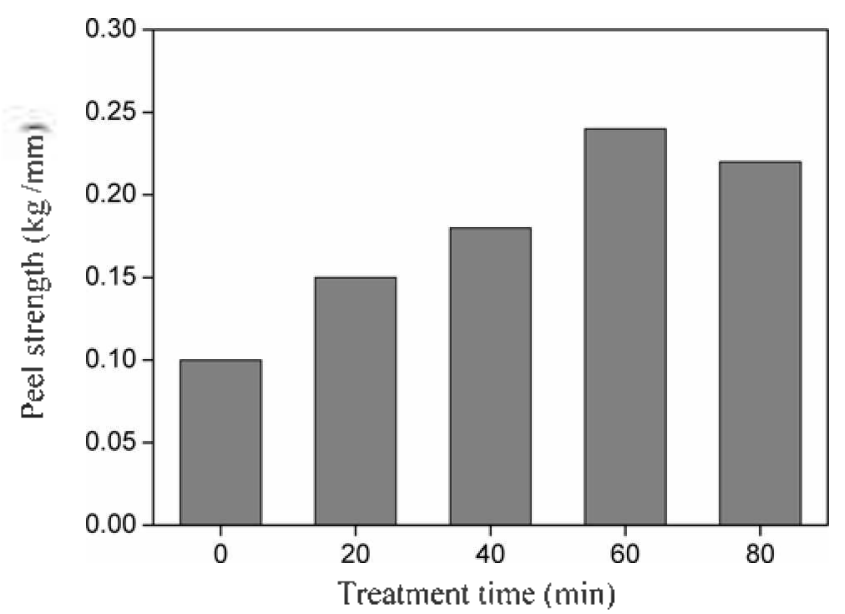

Figure 7. Peel strength of polyinide films as a function of treatment tine.

sion strengths are much higher in $\mathrm{KOH}$-treated polyimide/ aluminum systems than that of the pristine polyimide/ aluminum system. The present data indicate that the peel strength was increased from about $0.1 \mathrm{~kg} / \mathrm{mm}$ for the pure polyimide to about $0.24 \mathrm{~kg} / \mathrm{mm}$ for the $\mathrm{KOH}$-treated polyimide. The increased formation of the functional groups identified as $\mathrm{C}=\mathrm{O}$ and $\mathrm{O}-\mathrm{C}-\mathrm{O}$ bonds. as shown by the increase in the $\mathrm{O}_{1 /} / \mathrm{C}_{1 \mathrm{~s}}$ in Table 3. may contribute to the enhanced chemical interactions between polyimide and aluminum surfaces resulting in an increase in the measured peel strengths. ${ }^{23}$

\section{Conclusions}

In this work, it was found that $\mathrm{KOH}$ treatment introduced carbon-oxygen functional groups onto the polyimide surfaces. The $\mathrm{O}_{15} / \mathrm{C}_{15}$ ratios of the $\mathrm{KOH}$-treated poly imides increased as a function of the treatment time. resulting in enhancing the surface free energy. Also. the $R a$ and RMS of the film surfaces. confirmed by AFM observation. were greatly' increased by $\mathrm{KOH}$ treatments. The adhesion strengths at interfaces between the treated polyimide film and the aluminum matrix showed the superior increments. which were attributed to the strong interaction between the oxygencontaining groups of polyimide and aluminum film. These results could be explained by the increment of the polarity and hydrophilicity of the polyimide surfaces and roughness. due to the increase of specific surface area by $\mathrm{KOH}$ treatment.

\section{References}

1. Tew: G. N. J. Am. Chem. Soc. 2006, 128.3104

2. Khongtong. S.: Ferguson. G. S. J. Ant. Chent. Soc. $2002.12+.7254$.

3. Liaw: D.-T.: Chang. F.-C.: Leung. M.: Chou. M.-Y.: Muellen. K. Macromolecules 2015.38 .4024$.

4. Park. S. J.: Kim, H. S.; Jin. F. L. J. Colloid Interface Sci. 2005. 288. 238.

5. Kim. Y.-H: Kim, H.-S.; Kwon. S.-K. Hacromolecules 2005. 38. 7950 .

6. Tummala. R. R.: Rymaszewski. E. J. Microelectronics Pachaging Hamdbook: Van Nostrand Reinhold: New York. U. S. A.. 1989: p 54.

7. Ling. Q.-D: Chang. F.-C.; Song. Y. Zhu. C.-X: Liaw. D.-J.; Chan. D. S.-H.: Kang. E.-T: Neoh, K.-G. J. Am. Chem Soc. 2006. 128.8732

8. Zhang. F.: Jia. Z.: Srinivasan. M. P. Lamgntuir 2005. 21. 3389.

9. Park. S. J.: Cho. K. S.: Kim. S. H. J. Colloid Interface Sci. 2004. 272. 384 .

10. Manzione. T. L. Plastic Packaging of Aficroelectronic Devices: Van Nostrand Reinhold: New York. U. S. A.. 1990; p 87.

11. Murdey. R.: Stuckless, J. T. J. Am. Chem. Soc. 2003, 125. 3995.

12. Honma. M.: Hirata. K.: Nose. T. Appl. Phns. Lett. 2006. 88. 33513

13. Butoi. C. I.: Steetr. M. L.: Peers. J. R. D.: Fisher. E. R. J. Phos. Chem. B 2001. 105.5957.

14. Helt. J. M.: Drain. C. M.: Bazzan. G. J. Am. Chem. Soc. 2006. 128. 9371.

15. Ramos. M. D. I'accm 2002. 64. 255

16. Acevado. M.: Harris. F. W. Polymer 1994, 35. 4456.

17. Thanuja. J.: Srinivasan. M. J. Polym. Sci. Polym. Chem. 1988, 26. 1697.

18. Park. S. J.: Lee. H. Y. J. Colloid Interface Sci. 2005, 285. 267

19. Fowkes. F. M. d. Plns. Chem 1963. 67, 2538.

20. Park. S. I. Interfacial Forces and Fields: Theon and Applicationts: Hsu. J. P.. Ed.: Marcel Dekker: New York. U. S. A.. 1999: p 394.

21. Murakami. T.: Kuroda. S.: Osawa. Z. J. Colloid Interface Sci 1998. 202,37

22. Shirahata, N. Hozumi. A. Chem. Haten 2005. 17,20. 